\title{
Patrimonio digital: obras renacidas, una nueva vida para las "obras fuera del circuito comercial"
}

Digital heritage: reborn works, a new life for out-of-print works"

Luis-Fernando RAMOS-SıMÓN, Manuel BLÁZQUEZ OCHANDO

Facultad de Documentación, Universidad Complutense de Madrid, España, Iframoss@ucm.es, manublaz@ucm.es

\section{Resumen}

El presente artículo forma parte de una investigación dedicada a las obras protegidas por derechos de autor que están fuera de los circuitos comerciales tradicionales, porque se han dejado de editar o sus titulares no están localizados, pero que en la actualidad gracias a la digitalización y a la venta de ejemplares en línea pueden recobrar su valor comercial en Internet. Se inicia con un estudio terminológico y su significado en España, en donde se han utilizado distintos vocablos para designar esta realidad. La base empírica del estudio son 80.165 obras seleccionadas a partir de la colección de la biblioteca de la Universidad Complutense de Madrid, la mayoría publicadas entre los años 1940 y 2000 . Las obras se han prestado más de 10 veces entre los años 2010 y 2017, por lo tanto, tienen el sesgo de ser demandadas, aun muchos años después de su publicación, pero al tiempo nos permiten comparar su vitalidad en las bibliotecas respecto a los catálogos comerciales. Los resultados ponen de relieve diferencias significativas en comparación con los datos manejados por los editores. En efecto, el mercado es muy dinámico y la mayoría de estas obras se encuentran fácilmente en los catálogos comerciales en línea.

Palabras clave: Obras fuera de circuito comercial. Digitalización del patrimonio cultural. Derechos de autor. Libros descatalogados. Obras huérfanas. Obras renacidas. Universidad Complutense de Madrid. España.

\section{Introducción}

Hace unos meses, en medio de una investigación sobre la digitalización del patrimonio cultural, solicitamos unos datos a nuestra Biblioteca, sobre el acceso y uso de la colección digital. La Universidad Complutense fue la primera de Europa continental en acordar con Google la digitalización de su patrimonio bibliográfico, en la actualidad se han digitalizado 145.000 obras de su fondo antiguo. Los datos solicitados tenían como función ilustrar una conferencia y nos llenaron de sorpresa a todos los investigadores. Son los que se muestran en la tabla I. En efecto, lo sorprendente está en que casi un $20 \%$ de los libros visitados en la Colección Digital Complutense digitalizada por Google, en los primeros meses de 2017, corresponde a obras en latín, además, es remarcable la cantidad absoluta: supera ampliamente los dos millones de consultas. Por poner una referencia sobre una cantidad tan fabulosa, esa cifra

\begin{abstract}
article is part of a research project dedicated to copyright works that are out of traditional commercial circuits, either because they are out of print or their right holders are not located, but now, thanks to digitization and online selling, are recovering their commercial value. First, a terminological study and its meaning in Spanish editorial sector, where different words have been used to design this reality, is provided. The empirical base of study are 80,165 works selected from the library collection of the Complutense University of Madrid, most of them published between 1940 and 2000. These works have been lent more than 10 times between 2010 and 2017; therefore, they are being demanded even many years after their publication, but at the same time they allow us to compare their vitality in the libraries with that of the commercial catalogues. Results highlight the differences with the data handled by the editors. Indeed, the book market is very dynamic and most of these works are easily found in online commercial catalogues.
\end{abstract}

Keywords: Out-of-commerce works. Digitization of cultural heritage. Copyright. Out-of-print books. Orphan works. Reborn works. Universidad Complutense de Madrid. Spain.

es más del doble de los préstamos de libros en un año normal de toda la Universidad.

\begin{tabular}{lr}
\hline Español & 6.729 .375 \\
\hline Latín & 2.128 .276 \\
\hline Francés & 1.574 .204 \\
\hline Italiano & 528.241 \\
\hline Inglés & 379.317 \\
\hline Portugués & 173.879 \\
\hline Otras lenguas & 312.342 \\
\hline Total Accesos & 11.825 .634 \\
\hline
\end{tabular}

Tabla I. Acceso, por lenguas, a la colección de libros de la UCM, digitalizados por Google (últimos 6 meses anteriores a junio 2017) 
Sobre todo, nos lleva a muchas reflexiones, algunas de ellas muy elementales sobre la difusión de la cultura en Internet y la capacidad para encontrar nuevos públicos y nuevos usos. Sólo una pregunta para centrar el tema: ¿Puede alguien pensar y/o afirmar que estas obras en dominio público y otros miles de obras agotadas y/o huérfanas depositadas en instituciones culturales están fuera de los circuitos comerciales?

La nueva propuesta de Directiva Europea sobre derechos de autor, presentada por la Comisión Europea (2016b, p. 593 final) al Parlamento Europeo, regula el uso de obras que están fuera del circuito comercial por parte de las instituciones del patrimonio cultural, con miras a su digitalización y puesta en línea.

Inicialmente, la expresión "obras fuera del circuito comercial" se refiere tanto a las creaciones agotadas y en desuso, como a las huérfanas. Entiéndase que todas las obras huérfanas, por definición, están abandonadas por sus titulares, por lo que será habitual que se encuentren fuera de distribución comercial (descatalogadas) e incluso agotadas, ya que ambos términos se emplean indistintamente en muchas ocasiones. Al haberse aprobado en la Directiva de la Unión Europea de 2012 un tratamiento específico sobre las obras huérfanas, éstas han adquirido una naturaleza y regulación precisa. En tanto que los términos obra descatalogada o fuera de comercio se reservan - de forma un tanto imprecisa- para las obras cuyos titulares de derechos están identificados o localizados (Curto, 2017, p. 731), pero que por distintas razones sus obras son retiradas de los catálogos editoriales, ya sea porque se agota la edición, así como debido a situaciones en las que se decide saldar la edición o destruir los ejemplares, etc. Parece claro que la relación entre las obras huérfanas y las fuera de circuito comercial no está clara y se superpone (Bensamoun, 2014). Lo que está bien claro es que la calificación de una obra como huérfana está sujeta a una búsqueda diligente para identificar y localizar al autor, mientras que en muchas obras fuera de circuito comercial los titulares de derechos son conocidos.

Para comprender la evolución, conviene recordar brevemente que la iniciativa de la Comisión Europea (2005), denominada i2010: bibliotecas digitales expone su estrategia para la digitalización, la accesibilidad en línea y la conservación digital de la memoria colectiva de Europa. Más tarde, uno de los subgrupos de expertos creado al efecto (i2010: Digital Libraries High Level Expert Group - Copyright Subgroup (2007), publica unas recomendaciones referidas a las obras huérfanas y a lo que entonces se denominó "obras descatalogadas". En el caso de las obras huérfanas, los expertos recomiendan a los Estados miembro la adopción de un mecanismo, para todo tipo de obras, que permita usos comerciales y no comerciales a través de un reconocimiento mutuo de las soluciones. En cuanto a las obras descatalogadas, la solución que se apunta es crear un sistema de licencias, una base de datos común y un procedimiento de gestión de derechos. Con posterioridad, la Comisión Europea (2008a) publica una comunicación sobre los avances en la digitalización, en la que aborda, entre otros aspectos, la situación de las obras huérfanas y la de las obras agotadas o que ya no se distribuyen. En ambas se reconoce las dificultades para avanzar en soluciones para su digitalización debido a la identificación de derechos de autor y a las dificultades para conseguir las autorizaciones.

La inconcreción al delimitar este tipo de obras está presente en Francia y Alemania. En Francia se incorporó al Código de Propiedad Intelectual una legislación específica referida a "la explotación digital de los libros no disponibles del siglo XX", definición en la que se incluye todo libro publicado en Francia "antes del 1 de enero de 2001 que ya no sea objeto de comercialización por un editor y que actualmente no esté publicado en formato impreso o digital", según el artículo 1341 del mencionado Código. Esa misma legislación contempla la creación de una base de datos en la que se catalogarán dichos libros a cargo de la Biblioteca Nacional de Francia. Esta iniciativa, que pretendía digitalizar medio millón de libros, se vio paralizada por la sentencia de 16-11-2016 del Tribunal de Justicia de la Unión Europea (asunto C301/2015). Por su parte, en Alemania se ha adoptado la misma denominación de "obras fuera del circuito comercial" para promover el proceso de digitalización de obras impresas publicadas antes de 1966, de modo que si una entidad de gestión de derechos firma un acuerdo para digitalizar este tipo de obras debe inscribirlo previamente en un registro específico, dependiente del registro alemán de patentes y marcas (DPMA).

Estos conceptos que identifican a las obras huérfanas, descatalogadas, agotadas y/o fuera de distribución se suelen contraponer a los títulos en el mercado o títulos vivos. Millán (2002, p. 403), hace una descripción precisa de esta ecología del libro: Por título vivo se entiende la "reunión de títulos editados disponibles en el mercado a través de los diferentes sistemas de comercialización y venta de libros. Junto a los libros descatalogados o agotados que, eventualmente, pueden obtenerse en mercados de lance, ocasión o segunda mano, como librerías 'de viejo' o ferias del libro antiguo, conforman el patrimonio bibliográfico". 
Por otra parte, la "clave de bóveda" de la industria editorial es la construcción del catálogo, en palabras del máximo responsable de la industria editorial española, A. Ávila (Millán, 2002, p. 66). Precisaremos más adelante estos conceptos.

\section{Objetivos}

El objetivo principal de este artículo es conocer la proporción y características generales de las llamadas "obras fuera del circuito comercial" existentes en las colecciones de las bibliotecas para demostrar su gran interés y posible visibilidad en un entorno digital, así como identificar si hay unas características comunes en estas obras. Adicionalmente, se trata de investigar las posibilidades de digitalización y las ventajas de su puesta en línea que lejos de ese significado de obras excluidas, pueden alcanzar una nueva vida. Todo ello orientado a poner en línea el rico patrimonio cultural del siglo $\mathrm{XX}$, en particular referido a este tipo de obras perdidas y olvidadas que por su interés deberían ser puestas en línea antes de que se produzca su entrada en el dominio público y evitar así que se forme un profundo "agujero negro" que impida o retrase el acceso a una rica parte del patrimonio cultural del siglo XX.

\section{Metodología}

Además de un amplio estudio documental de las fuentes que profundizan en la importancia de incorporar las obras huérfanas y descatalogadas al patrimonio digital, se ha realizado un detallado estudio de las características de este tipo de obras. En particular, se ha partido del estudio de las obras con mayor número de préstamos de la colección de la Universidad Complutense. Esos datos muestran que entre los años 2010 y 2017, 80.165 obras fueron prestadas más de 10 veces. La mayor parte de las obras de la muestra fueron editadas en España entre 1940 y 2000. Estos datos se trataron globalmente y para contrastar la validez de los resultados se seleccionaron las 100 obras más prestadas en tres años elegidos de forma aleatoria, tomando como hitos los años 1940 y 2000 . El resultado de la selección fueron las cien obras más prestadas de 1947, 1967 y 1987 , además de las cien obras con más préstamos acumulados de las obras solicitadas entre 2010 y 2017.

La selección de estas cuatro muestras se justifica en que a priori son obras protegidas y su edición pertenece a períodos en que la probable entrada en dominio público de las obras se producirá dentro de varias décadas (en términos generales, en España en la actualidad, entran en dominio público las obras de los autores fallecidos hace 80 años, 1937). Asimismo, por su criterio de selección - son obras demandadas en los años recientes- demuestran un notable interés para un grupo de usuarios muy representativos, como son los estudiantes universitarios y los investigadores quienes han seguido demandando esas obras muchos años después de su publicación. Ambos aspectos - demanda de los usuarios y falta de interés o dificultad de los editores por atender esta oferta- justifican que se instrumenten los mecanismos para su digitalización y puesta en línea.

\section{Desarrollo}

\subsection{Las obras fuera del circuito comercial}

El término "obras fuera del circuito comercial" se incorpora en la legislación y en el sector de cultural a través de la Directiva de obras huérfanas de 2012 (parte expositiva, considerando 4) y previamente en los acuerdos que firman los representantes de la industria de contenidos conocido como Acuerdo sobre búsqueda diligente de obras huérfanas (Comisión Europea, 2008b) y sobre principios para digitalización y puesta en línea de obras descatalogadas (MoU), en 2011, aunque el segundo acuerdo estaba sólo orientado a los libros y a las publicaciones periódicas. Ambos tienen su origen en los resultados del proyecto promovido por la Comisión Europea "eBibliotecas Digitales 2010" (2006).

En la propuesta de Directiva europea sobre los derechos de autor en el mercado único digital, presentada en 2016, ya en fase avanzada de aprobación, se considera que una creación está fuera del circuito comercial cuando la totalidad de la obra u otra prestación, en todas sus traducciones, versiones y manifestaciones, no está a disposición del público a través de los canales comerciales habituales y no pueda esperarse razonablemente que lo esté. La definición se aplica a todo tipo de obras, sean libros, revistas especializadas, audiovisual, artes visuales o sonido. Este término debe de ser bien estudiado porque abarca posibles situaciones muy diferentes, tanto en la consideración comercial de las obras, como por la protección de las mismas en cuanto a los derechos de propiedad intelectual de autores y titulares. En tal sentido, no tienen la misma consideración legal las obras nuevas que las obras usadas o las descatalogadas, y mucho menos las impresas que las digitalizadas.

En general, si es cierto que las obras se retiran del catálogo porque no quedan ejemplares disponibles - sería el caso de las obras agotadas--, con frecuencia esa decisión responde a estrategias comerciales de otra índole, ya sea porque se 
desea liquidar la edición o simplemente para aliviar el número de libros en stock y los costes correspondientes, ante la perspectiva de una edición con venta muy lenta y poco rentable. En tales situaciones, unas veces se destruyen los ejemplares, pero con frecuencia se derivan dichos ejemplares a "tiendas de 24 horas" o a librerías de lance o de segunda mano, de tal modo que aunque están fuera del circuito de las librerías no dejan de formar parte de la oferta al público, por lo que no salen del circuito comercial del libro, aunque sí de las librerías. Mucho menos cuando estas obras se integran en los canales de Internet y pasa a formar parte de la oferta de grandes operadores, como Amazon, o en España, La Casa del Libro, Todos Tus Libros o Iberlibro, filial de la primera.

\subsection{Evolución del concepto y la práctica profesional en España}

Esta circunstancia nos lleva a plantear cuándo una obra está descatalogada o por aclarar conceptos, sale fuera del circuito comercial tradicional. En España, la práctica profesional, la costumbre, identifica a las obras descatalogadas con las agotadas: cuando se ha terminado de vender la edición o quedan pocos ejemplares, el editor retira la obra del catálogo. A partir de entonces sólo es posible encontrarla en las librerías de lance o de viejo. La costumbre así parece confirmarlo.

En los contrato-tipo recomendados por el Instituto Nacional del Libro Español (INLE) a principios de los años setenta del siglo XX (Cendán, 1972, p. 351 y ss.) se establecía con carácter facultativo que, si la obra "hubiera de ser vendida a precio de saldo, el autor podrá adquirir (...) la totalidad de los ejemplares que el editor salde" (Ibidem, p. 369). Asimismo, en un segundo supuesto, el editor puede disponer la destrucción o inutilización de los ejemplares, pero esa decisión se la habrá de comunicar al autor quien podrá comprar hasta 50 ejemplares al mismo precio, si bien estos libros "no podrán tener destino comercial". Estas estipulaciones se establecen tanto en el contrato-tipo general, como en la edición de colecciones populares y en la edición de libros de club.

En esa misma época se recopilan y publican los usos y costumbres del sector, a través de la llamada "Ordenación del comercio interior del libro" (Cendán, 402). Dicha normativa sectorial, en la que no aparece el término "obra descatalogada", señala (art.13) que son libros de saldo: los libros usados ajenos al comercio de la librería anticuada (es decir, se excluye al libro antiguo); los restos de edición en poder de los editores y distribuidores; y los libros no vendidos en poder de los libreros.
Por entonces, estos libros de saldo sólo podían ser vendidos en los establecimientos autorizados, es decir, en las librerías de lance y en las librerías de nuevo que reserven un espacio "perfectamente diferenciado". Los libros usados y los de saldo tienen un tratamiento distinto. Los primeros, por su característica de usados, pueden ser vendidos sin conocimiento de los editores. Mientras que los "restos de edición" y "los libros no vendidos en poder de los libreros" han de seguir el procedimiento estrictamente regulado: declaración del editor transcurrido al menos 24 meses desde la puesta en venta y visto bueno de la autoridad administrativa (el INLE) o notificación del editor a distribuidores y libreros a los que habrá de abrir un plazo de liquidación de ejemplares. Asimismo, la declaración de saldo también puede iniciarse por distribuidores y libreros, opción también sujeta a un mecanismo muy prolijo en cuanto a condiciones y régimen de precios durante los dos primeros años desde la declaración de saldo. La normativa deja claro que, en los catálogos de libros de ocasión, solamente podrán anunciarse obras de esta índole, "no permitiéndose catálogos mixtos de obras nuevas y de saldo" (las grandes librerías que operan en Internet prescinden de esta regla claramente).

Esta última consideración deja a las claras la escasa implantación del término descatalogación en un sector en el que se han reconocido al menos dos tipos de catálogos, unas veces para dar cabida a obras nuevas y otras para las usadas o agotadas. No en vano, en la edición del diccionario de la RAE (2001) a descatalogar se le da el sentido de "quitar un libro, un disco, un cuadro, etc., del catálogo del que forma parte", sin precisar más. En tanto que agotar, en su segunda acepción, significa "gastar del todo, consumir" y cita como ejemplo "agotarse una edición". En el Diccionario de sinónimos (Sainz de Robles, 1984) no tiene entrada el término descatalogado, sí lo tiene el de agotado, pero ninguno de sus sinónimos refiere a términos del sector del libro. Tampoco el Diccionario ideológico (Casares, 1975) ofrece respuesta sobre ninguno de los dos términos, en donde ni siquiera aparece el término descatalogado.

De hecho, el término no se generaliza hasta que es vinculado al precio fijo del libro (RD $2828 / 1979$ ), en la actualidad regulado en la Ley de la lectura (2007), en donde se excluye del precio fijo del libro, entre otros casos, a las ediciones agotadas y a los libros descatalogados. Ofrece a continuación una definición clara de esa situación: "entiende que un libro ha sido descatalogado por el editor cuando no aparezca en su último catálogo o lo comunique por escrito a sus 
canales de distribución y venta y a la Agencia española del ISBN o a las agencias autonómicas del ISBN. La oferta y exposición de estos libros deberá realizarse separada y suficientemente indicada de la de los libros sujetos a precio fijo" (art. $10 \mathrm{~h}$ ). Lo dispuesto más adelante en el articulado de esta Ley es coherente con lo regulado en el contrato de edición (LPI, 1996-2018), en cuyo artículo 67 dispone que el editor no podrá, sin el consentimiento del autor, vender la edición a saldo hasta pasados dos años. En tal caso, el autor tiene derecho a optar entre ejercer el derecho de tanteo sobre el precio de saldo o a percibir el $10 \%$ de lo facturado por el editor. En el caso de que el editor decida destruir el resto de la edición, el autor puede pedir que se le entreguen todos o parte de los ejemplares, aunque el autor no podrá dedicar éstos a usos comerciales. Esta opción de enajenar los ejemplares por parte del editor y el derecho de tanteo del autor también está contemplada en los tres años posteriores a la extinción del contrato (art. 70, LPI).

De todo lo anterior parece claro que el sistema de fijación de precios es desde hace muchos años determinante para el establecimiento de los diversos mercados del libro, en donde al menos podemos distinguir: mercado del libro nuevo, del libro usado, de saldo, así como el del libro antiguo o de bibliofilia, a los que hay que añadir las nuevas modalidades, como el e-libro o libro electrónico y el audiolibro. Sólo la particularidad del precio fijo y la especificidad de la doctrina de la primera venta justifican un esquema de mercados separados. Sobre ambos aspectos remitimos a sendos estudios específicos. Por un lado, nos remitimos en particular a Carbajo Cascón (2012, 479 y ss.), en donde se analizan los aspectos relacionados con la transmisión de derechos para la edición y distribución de libros y publicaciones digitales, así como la difícil aplicación del precio fijo en el ámbito del e-libro. En cuanto, a la aplicación de la doctrina de la primera venta, regulada en el art. 19 de la Ley de Propiedad Intelectual, supone que cuando la venta se lleve a cabo dentro de la Unión Europea, "por el propio titular del derecho o con su consentimiento, este derecho se agotará con la primera...", lo que supone que el autor y el editor tienen derecho a recibir remuneración por la venta del libro nuevo y también por el descatalogado, pero no por el libro usado. El agotamiento o extinción del derecho de distribución mediante la venta tiene su fundamento en que el control "no debe prolongarse después de la primera enajenación de su obra, con lo que ya ve recompensado su trabajo" el autor, afirma Rivero Hernández, F. (2007, p. 320). No obstante, poco más adelante, menciona que varias teorías cuestionan: "si el agotamiento se refiere sólo a la enajenación de obras corporales o también las incorporales" cuestión nada intrascendente que incide sobre los derechos sobre las obras y prestaciones electrónicas. También se pregunta si el agotamiento afecta a algunos actos económicos y jurídicos posteriores a la primera enajenación de las copias (en particular el alquiler y préstamo) que en el mercado secundario van a perjudicar indirectamente al autor.

\subsection{La extensión del concepto a toda clase} de obras (impresas, audiovisuales...)

Así llegamos al concepto con el que se designa a este conjunto de obras y materiales creativos, protegidos por los derechos de autor, que una vez cumplido su ciclo comercial pueden adquirir nueva vida, tras su digitalización y puesta en línea por las instituciones culturales tal como contempla la Directiva europea de Derechos de Autor en Internet de 2001. La denominación de este grupo de obras que configura el art. 7 de la propuesta de Directiva de 2016 hasta su denominación definitiva de "obras fuera del circuito comercial" ha tenido algunas variantes. En "El Nuevo Renacimiento" (Comisión Europea, 2011a) se llama a este conjunto de creaciones "obras fuera de circulación" y ese Comité de Sabios que lo elaboró, recomienda ponerlas en línea en las instituciones culturales, igual que a las obras huérfanas, en razón de que forman parte del patrimonio cultural.

En cuanto a las obras fuera del circuito comercial, son obras todavía bajo la protección de los derechos de autor, copias que no están comercialmente disponibles para el público, a través de los canales habituales de acceso y que no se espera que lleguen a estar disponibles en el futuro. Los derechos que es necesario conseguir son los de reproducción y los derechos de comunicación pública para la difusión en línea, aunque puede también incluir los derechos de distribución (Comisión Europea, 2016a, p. 65). El panorama que trata este estudio sobre las obras fuera del circuito comercial es bastante difuso: hay muchas obras, de las que se sabe poco, las obras son importantes y se estima que los costes serán altos, sin poder concretar cifras, hay pocas licencias disponibles y los autores no están incorporados a las entidades de gestión por lo que sólo cabe la negociación individual o las licencias colectivas extendidas que precisa de una legislación previa.

Aunque con el término se pretende designar todo tipo de obras, la delimitación de las obras fuera del circuito comercial en el ámbito audiovisual es más compleja que en los libros. Se considera cine patrimonial (film de patrimonie, en francés; heritage film, en inglés) a las películas producidas al menos hace 10 años. El European Audiovisual 
Observatory considera tales al $20 \%$ de las películas, son una pequeña parte y sólo son significativas en uno o dos mercados, en tal sentido, suponen el $47 \%$ de las películas emitidas por televisión.

La definición de las películas del patrimonio es difícil. Por un lado, incluye una variedad de obras diferentes que van desde películas clásicas a cultas (Comisión Europea, 2016b, p. 77). Como afirma el European Audiovisual Observatory (2016), la película patrimonial es definida tanto como una categoría basada en la fecha de lanzamiento de una obra cinematográfica, como otros criterios de selección tales como su valor cultural o histórico y que pueden evolucionar considerablemente a lo largo del tiempo. Podemos considerar que una obra cinematográfica es parte del patrimonio 10 años después de su lanzamiento, habiendo completado un primer ciclo comercial a través de varios canales de distribución (salas de exhibición, televisiones, vídeo doméstico...). Esto no excluye que todavía pueda tener vida comercial. También está claro que el cine y las películas del patrimonio no son una categoría homogénea con relación a su potencial comercial.

\subsection{De obras fuera del circuito comercial a obras renacidas}

La aplicación de un régimen legal común a todas estas obras que se han dejado de editar debería tener un enfoque más positivo que el que sugiere "obras fuera del circuito comercial". Estas obras, difíciles de encontrar, podrían tener una segunda vida en Internet, tan boyante como el de las obras en latín que comentábamos al inicio del artículo. Su puesta en línea facilitaría la captación de nuevos públicos y ayudaría a taponar ese enorme "agujero negro" en el acceso a la cultura del siglo XX que las leyes de propiedad intelectual y la falta de mecanismos de acuerdo no consiguen resolver, tan bien glosado en el informe El Nuevo renacimiento (Comisión Europea, 2011b).

Por lo tanto, el término "obras fuera del circuito comercial" está distorsionado y es inadecuado para describir la realidad de las obras una vez que sean accesibles en Internet. Por un lado, el término sólo mira al aspecto comercial de las obras, ocultando el lado cultural y de difusión que conlleva la digitalización de puesta en línea de las obras. Por el contrario, hay otros términos que describen mejor la nueva realidad. Es cierto que obras abandonadas, obras perdidas, obras cautivas... pueden conllevar una carga negativa $o$ parcial en cuanto a los partícipes en la cadena creativa. Sin embargo, términos como "obras renacidas" u obras recuperadas reflejan bien el pro- ceso que convierta a estas obras en la gran novedad de la cultura digital que nos devuelve para el futuro las obras del pasado. Son obras renacidas porque aun habiendo sido ya creadas, surgen con nuevos formatos, obras a las que se pueden aplicar herramientas o algoritmos que nos descubrirán nuevos aspectos del pasado y, por lo tanto, nos ayudarán a conocer el futuro. Una edición comentada de El Quijote de mediados del siglo XX, es miserable considerarla una obra fuera de comercio - desde todos los puntos de vista-, pero probablemente nos arroje más luz sobre cómo se pensaba y cómo se quería que pensáramos que muchos ensayos sesudos y necesariamente selectivos publicados ayer. Así, pues, llamemos obras renacidas a todo este conjunto de creaciones que claman por ser accesibles en Internet. Como en el Nuevo Renacimiento, pensamos que "la digitalización inspira nueva vida al material del pasado y lo convierte en una baza impresionante para el usuario individual y en un importante elemento de la economía digital", iniciativa que debe ser asumida por el sector público (Ibidem).

Por otro lado, en un mercado tan dinámico como el del libro, tampoco es cierto que las obras que están en poder de sus compradores están fuera de mercado, es como decir que las acciones de una sociedad que están en manos de sus propietarios - sin intercambiar durante muchos años en las Bolsas ni participar en las juntas anualesestán por esa razón fuera del mercado, valga el símil. Asimismo, esas obras que se señalan por los editores como fuera del ámbito comercial forman parte de un comercio diferente, en muchos casos más dinámico y valioso que otros. Como ha demostrado Bezos, creador de Amazon, los libros son unos de los mejores productos que se conocen para ser comercializados (Haro, 2014; Brandt, 2012).

Desgraciadamente, no pocas veces, se pueden traspasar los límites de la legalidad y del comercio honesto, como ponemos de relieve en los datos que aportamos a continuación. Si hay demanda, las obras serán suministradas desde cualquier lugar del mundo, rompiendo así el tejido productivo y cultural, como sucede cuando un libro nos llega desde cualquier confín del mundo a través de la venta en línea. Por lo tanto, el problema no sólo interesa a las bibliotecas, sino también a editores, autores y a toda la cadena de edición.

\section{Número y situación de las obras disponibles para digitalización}

Como hemos avanzado, estas obras que la nueva normativa de derechos de autor va a considerar 
disponibles para el proceso de digitalización, son obras depositadas en instituciones culturales, descatalogadas y/o usadas, a veces huérfanas, que precisan de la autorización del autor o titulares de los derechos para llevar a cabo actos de reproducción (la misma digitalización), distribución (tal como la posterior venta de ejemplares o préstamos), comunicación pública (la puesta en línea de la obra) y, en general, cualquier acto de explotación. La mayoría de las veces será el propio autor el titular único de estos derechos, pero dada la diversidad de situaciones en las que se encontrará la obra una vez digitalizada, es probable que sea precisa la participación del editor. Esto es debido a que con frecuencia pueda entrar en situaciones flagrantes de competencia desleal con la distribución en línea, de ahí el papel preferente que se otorga al editor de la edición impresa en todas las legislaciones específicas aprobadas (Francia, Reino Unido, Alemania...), como mencionábamos anteriormente.

La primera cifra que interesa saber es el número total de títulos que se han publicado en España. Si tomamos como punto de partida el año 1940 y el final el año 2000 , el número de títulos asciende a 1.345.727, según se desprende de los datos anuales facilitados por el Instituto Nacional de Estadística. La cifra debe ser ponderada por el número de títulos reimpresos y reeditados. Si ponemos en consideración las mismas proporciones del año 2000 para el conjunto de la producción editorial del período 1940-2000, la edición de novedades $(52,9 \%$ de la producción anual de títulos) vendría a ser de unas 711.890 obras nuevas.

Si en el año 2000, según los editores, el número total de títulos vivos se cifraba en 251.435, (FGEE, 2000), sin poder determinar la forma de cálculo. A partir de ahí, vendríamos a obtener una cifra de títulos de obras agotadas y descatalogadas del orden de 460.455 editadas antes del año 2000. Es sorprende que estas cifras sean bastante coincidentes con el objetivo marcado en Francia tras la aprobación de la legislación sobre obras inéditas en donde se cuantificaba el objetivo en 500.000 obras.

Con estos datos, deberíamos poder conseguir una estimación porcentual sobre la diferente situación de las obras con vistas a su digitalización y puesta en línea por instituciones culturales, bien sea previa declaración de obra huérfana, a través de su consideración como obras fuera de circuito comercial o mediante excepciones legales que sean de aplicación. Para ello se ha procedido a someter a tratamiento informático la muestra de las 80.165 obras más prestadas en el catálogo de la Universidad Complutense en el período 2010-
17 y a contrastar su presencia en diferentes catálogos. De ahí podremos inducir cuál es la situación real de las obras publicadas en España de cara a su integración en el patrimonio digital. Los catálogos bibliográficos que hemos manejado han sido divididos en dos categorías.

- Catálogos funcionales: orientados a dar información bibliográfica. Se han manejado el propio de la BUCM, del que se han obtenido los datos muestrales; Rebiun; BNE e ISBN-Dilve.

- Catálogos comerciales: Catálogos de libros y bases de datos orientados a promover la venta de obras. Se han seleccionado: Amazon, Todos Tus libros, Iberlibro y Google Libros. Sobre este último, cabe precisar su situación singular. Por un lado, facilita información y da acceso a millones de libros en dominio público y a fragmentos de obras protegidas que han sido digitalizadas legalmente. En tal sentido, juega un papel funcional de información bibliográfica. Sin embargo, también promueve la adquisición de obras a través del mismo sitio Google Libros.

Los resultados obtenidos se comentan a continuación. La figura 1 muestra la estimación de presencia de las obras en los catálogos comerciales en línea.

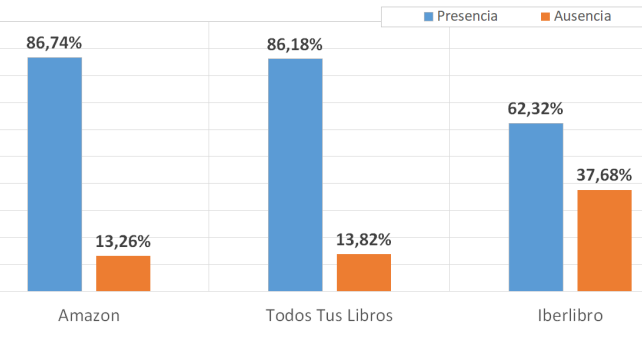

Figura 1. Estimación en porcentajes (\%) de presencia, de las obras en los catálogos comerciales en línea

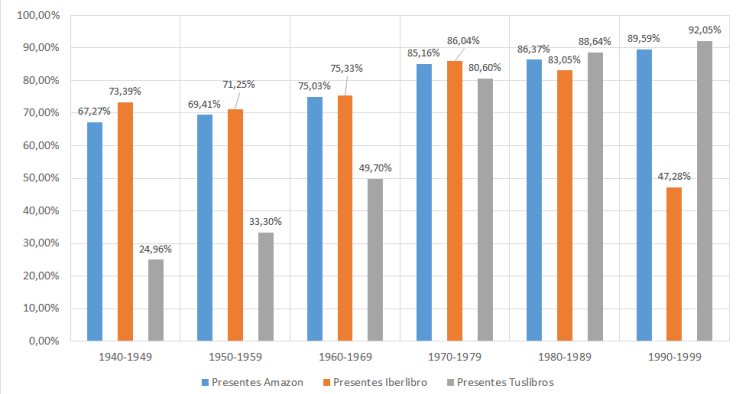

Figura 2. Estimación en porcentajes (\%) por décadas, de la presencia de obras en los catálogos comerciales en línea 
La figura 2 representa la estimación por décadas de la presencia de obras en los catálogos comerciales en línea (1940-2000).

La figura 3 muestra la estimación por décadas de la ausencia de obras en los catálogos comerciales en línea.

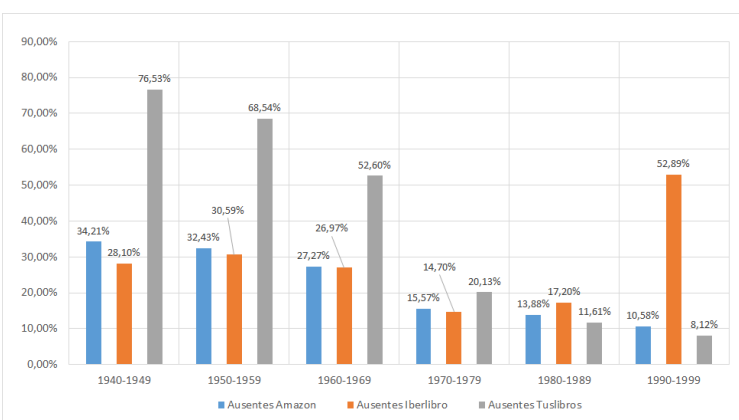

Figura 3. Estimación en porcentajes (\%) por décadas, de la ausencia de obras en los catálogos comerciales en línea

La figura 4 señala la estimación de obras fuera del circuito comercial por décadas. En estos datos se tiene en cuenta que los libros estén ausentes de los catálogos comerciales y además en el catálogo del ISBN, o bien que estén en el ISBN, pero como "no disponible". Añadido a esto se agrega que no sean obras traducidas o versionadas.

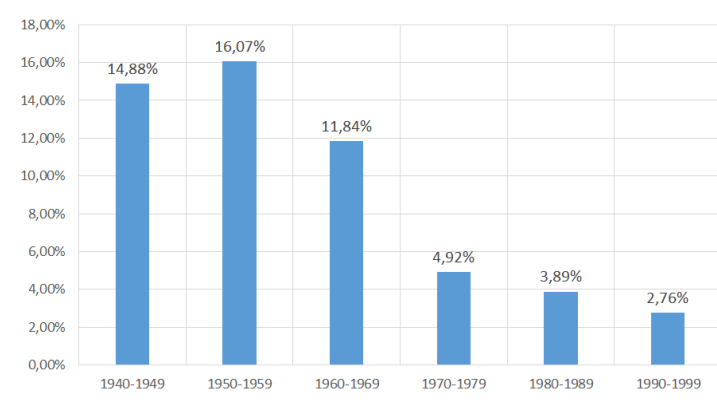

Figura 4. Estimación en porcentajes (\%) de obras fuera del circuito comercial

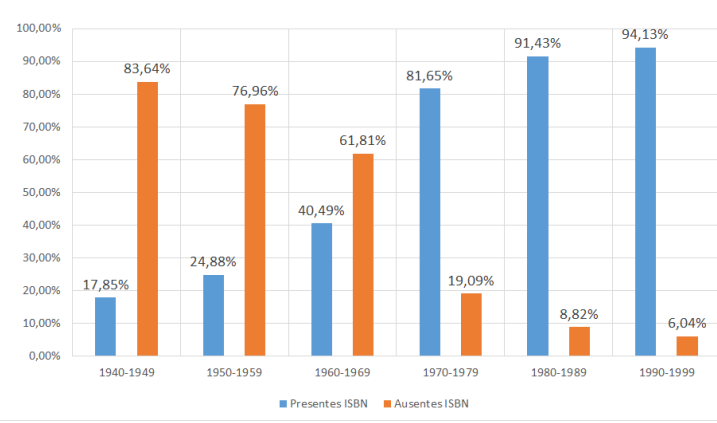

Figura 5. Estimación en porcentajes (\%) por décadas, de libros con ISBN (1940-2000)
La figura 5 ofrece una estimación de la evolución por décadas de libros con ISBN entre 1940 y 2000.

Por otro lado, los resultados del tratamiento masivo de los datos globales, las muestras aleatorias y los gráficos nos proporcionan suficiente información para poder plantear una amplia discusión en torno a los siguientes puntos:

El número total de títulos vivos, es decir, de obras publicadas principalmente entre 1940 y 2000 que son accesibles en los catálogos comerciales, es casi del $87 \%$ en dos de los tres catálogos comerciales, con cifras muy similares. La evolución de los títulos vivos por décadas oscila entre $67 \%$ en los años cuarenta al 92\% en la década de los noventa, como es lógico, los datos reflejan un mayor número de títulos vivos conforme nos acercamos a la década actual. Esta evolución es más acusada en el catálogo de Todos tus libros, en donde se pasa del $25 \%$ al $92 \%$, respectivamente. Estos datos pueden reflejar bien la visión de la librería tradicional, más vinculada a las novedades editoriales, frente al mayor componente de libros usados que parece manejar Iberlibro, lo que justificaría la relativa baja presencia en este catálogo de obras editadas en los años noventa.

En sentido inverso, el gráfico de la figura 3 refleja este mismo enfoque, pero a la inversa. Corresponde con las obras descatalogadas y usadas, siendo muy difícil separar unas situaciones de otras, salvo que la discriminación se hiciera título a título. Es decir, en la lista de resultados obtenida tras las consultas figuran etiquetas de obras "usadas", "de segunda mano" y el problema radica en que los catálogos mezclan esta información con obras de novedades, resultando muy difícil su distinción por medios automáticos.

Un pequeño grupo de estas obras podrían ser potenciales obras huérfanas, aunque es poco probable, ya que son libros recordados por los usuarios y demandados al menos en las bibliotecas. La figura 4, muestra que el porcentaje de obras fuera de circuito comercial revela que está en torno al $15 \%$ en las décadas de los cuarenta y cincuenta y baja a menos del $5 \%$ a partir de los años setenta, lo que de otro modo refleja la vitalidad de las obras publicadas desde entonces.

El gráfico de la figura 5 nos permite observar que la vigencia del ISBN se ha extendido a los años precedentes a su implantación, a comienzos de la década de los setenta. Llama la atención que en la década anterior el $40 \%$ de los libros publicados está presente en el catálogo del ISBN e incluso se extiende a un $17 \%$ de los libros publicados en la década de los cuarenta. 
Respecto a las obras digitalizadas y que pueden ser accesibles parcial o totalmente, las muestras aleatorias analizadas, en una primera aproximación, muestran que entre un $20 \%$ y un $30 \%$ de las obras están digitalizadas, la mayoría por Google Books.

Es interesante tener una aproximación a la proporción de obras traducidas, por cuanto que, si fueran obras protegidas y la edición original no fuera en España, no podrían ser sometidas a un proceso de digitalización o declaración de obra huérfana. Las traducciones representan un porcentaje elevado de la edición anual (según la fuente consultada -INE o INLE- entre el 20$30 \%$ a mediados de los años setenta del siglo $X X$ ). En el año 2000 (Ministerio de Cultura, 2008, p. 9), el porcentaje de títulos traducidos sobre el total de títulos editados se cifraba en el $24,8 \%$, con muy pocas variaciones en los años que recoge la estadística (1990-2007). De otra parte, estas obras tienen una consideración importante en cuanto a la digitalización, por cuanto son obras derivadas, cuyo uso está sujeto a la autorización de la obra original, salvo que la obra traducida esté en dominio público. Los datos obtenidos en el tratamiento de la muestra global son algo más bajos que los mencionados (16\%), pero no muy alejados. La diferencia puede radicar en las características de la muestra utilizada que puede tener muchos manuales de asignaturas, muy prestados y de autores españoles.

\section{Conclusiones}

Los resultados analizados en la investigación ponen de relieve la diferencia de apreciación del fenómeno de las obras usadas, agotadas y descatalogadas (fuera del circuito comercial) según los datos que ofrece el sector editorial y lo que refleja el análisis de la muestra estudiada. El mercado del libro es muy dinámico y las obras raramente dejan de estar disponibles, los catálogos en línea accesibles en Internet incorporan indistintamente libros nuevos, usados y descatalogados, lo que supone un cambio notable en la configuración del mercado editorial.

El interés por digitalizar libros protegidos debe estar orientado a poner las obras a disposición de un público nuevo que prefiere el acceso digital y que ya utiliza poco el formato impreso en tareas de aprendizaje e investigación. A juzgar por lo que comentamos sobre la tabla 1 , es probable que el acceso a esas obras, una vez digitalizadas, se multiplique por varios ceros con relación al interés mostrados por acceder al préstamo bibliotecario tradicional. De ahí que propongamos "obras renacidas" para designar este tipo de obras que se digitalizan.
Los datos obtenidos desvelan una alta presencia de obras en los catálogos comerciales, próxima al $86 \%$. Esto significa que un $14 \%$ estarían fuera de estos catálogos, pero sólo un $4 \%$ se consideran fuera de comercio, al no encontrarse en el catálogo del ISBN o bien figurar expresamente como descatalogados. Del $4 \%$ puede deducirse que exista una proporción reducida de obras huérfanas, aunque este supuesto aún requiere de comprobaciones y cotejos manuales.

Las obras fuera del circuito comercial describen una gráfica idéntica a la ausencia de obras en el ISBN. Ello valida el resultado obtenido, ya que guarda una correlación lógica, esto es que el número de obras descatalogadas o No disponibles en el catálogo del ISBN, tampoco lo están en los principales catálogos comerciales. Ello puede comprobarse en los datos absolutos de la muestra. Amazon y Todos Tus Libros presentan una cifra de ausencias de 10.000 a 11.000 obras, muy próxima al catálogo del ISBN con 9.800 . Si se tiene en cuenta que 3.244 cumplen las condiciones para considerarse fuera de comercio, ello significa que corresponden a un $33 \%$.

La proporción de obras ya digitalizadas nos parece muy elevada (20-30\%), quizás sea debido a que en la muestra hay obras muy demandas en préstamo. Eso indicaría que ya hay una política clara en cuanto a las preferencias de digitalización, al tiempo que pondría de relieve el interés de nuestra investigación, de índole exclusivamente académica. La investigación aporta también datos interesantes en cuanto a futuras políticas de digitalización de obras en distintas esferas. Así, los datos muestras que frente a lo que a menudo se afirma, hay amplios sectores en los que la existencia de obras huérfanas es minoritaria. Asimismo, serían fáciles de detectar porque un volumen alto de préstamo de una obra, en una edición anticuada, revelaría un abandono de la misma por el autor y/o editor.

Por otro lado, una política de digitalización de este tipo de obras analizado en la muestra se vería muy condicionada por el alto porcentaje de obras traducidas que exigirían previamente -en la mayoría de los casos-obtener permiso del autor de la obra original si se quiere digitalizar la traducción antes de su entrada en el dominio público.

\section{Notas}

(1) Es importante, aclarar aquí que para el sector comercial/ editorial del libro, Cegal, considera librería, "los establecimientos especializados que comercialicen al por menor libros, lo que corresponde al epígrafe 4761 según la Clasificación Nacional de Actividades Económicas (CNAE2009) 2, excluyendo el comercio al por menor de libros antiguos o de segunda mano". Véase, Bravo, 2017, p.15-16 
2) Es muy difícil apreciar la diferencia entre ambos términos en la práctica. A efectos estadísticos la diferencia es como sigue: reedición, edición que se distingue de la anterior por algunas modificaciones introducidas en el contenido o en la presentación, requiere necesariamente nuevo ISBN; reimpresión es la impresión repetida de una publicación sobre el mismo molde o matriz de la primera impresión y que, al no incorporar modificaciones que afecten al contenido o presentación no requiere necesariamente un nuevo ISBN (Ministerio de Cultura, 2018).

\section{Agradecimiento}

Los autores agradecen a la Biblioteca de la Universidad Complutense las facilidades encontradas para la cesión de los datos aquí presentados.

\section{Referencias}

Bensamoun, Alexandra, 2014. The French out-of-commerce books law in the light of the European Orphan Works Directive. // Queen Mary Journal of Intellectual Property. 4:3, 213-225. https://doi.org/10.4337/qmjip.2014.03.03

Bravo Gil, Rafael et al. (2017) Observatorio de la librería: mapa de librerías en España 2016. Zaragoza: GegalOTRI Universidad de Zaragoza, Junio 2017. https:// www.cegal.es/wp-content/uploads/2017/11/MAPA-DELIBRER\%C3\%8DAS-2016_octubre-2017-final.pdf

Brandt, Richard L. (2012). Un click: Jeff Bezos y el auge de Amazon.com. Barcelona: Ediciones Gestión 2000.

Carbajo Cascón, Fernando (2012). Transmisión de derechos para la edición y distribución digitales de libros y publicaciones electrónicas. // Libros electrónicos y contenidos digitales en la sociedad del conocimiento: Mercado, servicios y derechos. Cordón García, J. A.; et al. (coord.). Madrid: Pirámide.

Casares, Julio (1975). Diccionario ideológico de la lengua española. Barcelona: Editorial Gustavo Gili.

Cendán Pazos, Fernando (1972). Edición y comercio del libro español 1900-1972. Madrid: Editora Nacional.

Comisión Europea (2006) Recomendación de 24 de agosto de 2006 sobre la digitalización y la accesibilidad en línea del material cultural y la conservación digital (2006/585/CE). DOCE, L 31/8/2006.

Comisión Europea (2007). i2010: Digital Libraries. Report on Digital Preservation, Orphan Works, and Out-of-Print Works. Selected Implementation Issues. http://ec.euro pa.eu/information_society/newsroom/cf/document.cfm?action=display\&doc_id $=295$

Comisión Europea (2008a) Comunicación sobre El patrimonio cultural europeo a un clic del ratón: Avances en la digitalización y el acceso en línea al material cultural y en la conservación digital en la UE. http://eur-lex.europa. eu/legal-content/ES/TXT/?uri=CELEX\%3A52008DC0513

Comisión Europea (2008b). Memorandum of Understanding on Diligent Search Guidelines for Orphan Works. http://www.ifap.ru/ofdocs/rest/rest0001.pdf

Comisión Europea (2011a). Recomendación de la Comisión de 27 de octubre de 2011 sobre la digitalización y accesibilidad en línea del material cultural y la conservación digital (2011/711/UE). // DO L 283 (29-10-2011).

Comisión Europea (2011b). The New Renaissance: Report of the "Comite des Sagés": Reflection group on the bringing Europe's cultural heritage online. http://ec.europa. eu/information_society/activities/digital_libraries/doc/refgroup/final_report_cds.pdf.

Comisión Europea (2011c). Memorandum of Understanding Key Principles on the Digitisation and Making Available of
Out-of-Commerce Works. http://ec.europa.eu/internal _market/copyright/docs/copyright-infso/20110920mou_en.pdf

Comisión Europea (2016a). Commission Staff Working Document Impact Assesment on on the modernisation of EU copyright rules Accompanying the document Proposal for a Directive of the European Parliament and of the Council on copyright in the Digital Single Market and Proposal for a Regulation of the European Parliament and of the Council laying down rules on the exercise of copyright and related rights applicable to certain online transmissions of broadcasting organisations and retransmissions of television and radio programmes. Primera parte. http://eur-lex.europa.eu/ legal-content/EN/TXT/?uri=CELEX\%3A52016SC0301

Comisión Europea (2016b). Propuesta de Directiva del Parlamento Europeo y del Consejo sobre los derechos de autor en el mercado único digital. // COM (2016) 593 final 2016/0280 (COD). https://ec.europa.eu/transparen cy/regdoc/rep/1/2016/ES/1-2016-593-ES-F1-1.PDF.

Curto, Mercedes (2017). El destino de los libros olvidados. // European Papers. 2:2, 731-741. https://doi.org/10.15166/ 2499-8249/156

Unión Europea (2012a). Conclusiones del Consejo, de 10 de mayo de 2012, sobre la digitalización y acceso en línea del material cultural y la conservación digital (2012/C 169/02). // Diario Oficial de la Unión Europea. C 169 (156-2012).

Unión Europea (2012b). Directiva 2012/28/UE del Parlamento Europeo y del Consejo, de 25 de octubre de 2012, sobre ciertos usos autorizados de las obras huérfanas. // Diario Oficial de la Unión Europea. 299 (27 de octubre de 2012) 5-12.

Federación de Gremios de Editores de España (2000) XIII Estudio del Comercio Interior del Libro 2000. http://federacioneditores.org/img/documentos/ComerciolnteriordelLibroenEspana2000.zip.

European Audiovisual Observatory (2016). (G.Fontaine P.Simone (autores), The Exploitation of Film Heritage Works in the Digital Era. Estrasburgo. https://rm.coe.int/ $16807835 \mathrm{~b} 8$

[LPI] (1996-2018). Real Decreto Legislativo 1/1996, de 12 de abril, por el que se aprueba el texto refundido de la Ley de Propiedad Intelectual, regularizando, aclarando y armonizando las disposiciones legales vigentes sobre la materia. Última actualización 14-4-2018. https://boe.es/buscar/act. php?id=BOE-A-1996-8930

Haro, José Luis de (2014). Un nuevo modelo de negocio a golpe de clic. Barcelona: Penguin Random House.

Millán, José Antonio (Coord.). La lectura en España: Informe 2002. Madrid: Federación de Gremios de Editores de España

Ministerio de Cultura (2008). La traducción editorial en España. http://www.mecd.gob.es/dam/jcr:9265cc2c-d155444d-9304-f7b254808235/traduccion-2007.pdf

Ministerio de Cultura (2018). CULTURABase. Madrid: Ministerio de Educacion y Formación profesional; Ministerio de Cultura y Deporte. http://www.mcu.es/culturabase/pdf/Estadistica_de_la_Edicion_Espanola_de_Libros_con_ISBN_2014.pdf

Rivero Hernández, F. (2007). Artículo 19. // Bercovitz, R. Comentarios a la Ley de Propiedad Intelectual. $3^{\mathrm{a}}$ ed. Madrid: Tecnos.

Sainz de Robles, Federico C. (1984). Diccionario español de sinónimos y antónimos. Madrid: Ed. Aguilar.

Enviado: 2018-04-01. Segunda versión: 2018-07-04. Aceptado: 2018-09-05. 